\title{
PARÂMETROS MORFOLÓGICOS DE Gypsophila paniculata L. CULTIVADA COM LODO DE ESGOTO ALCALINIZADO E ADUBAÇÃO FOSFATADA
}

\author{
Morphological parameters of Gypsophila Paniculata L. grown with sewage \\ sludge and phosphorus fertilization
}

Cyntia Maria Wachowicz ${ }^{I}$

BeatrizMonteSerrat ${ }^{2}$

\section{Resumo}

O presente trabalho foi conduzido em casa-de-vegetação com o objetivo de avaliar a influência de doses de lodo de esgoto alcalinizado e de adubação fosfatada no desenvolvimento da cultura da Gypsophila paniculata L. ("mosquitinho"). As doses de lodo testadas foram 0, 20, 40 e 60 tha ${ }^{-1}$ (em base úmida) e os tratamentos de adubação fosfatada variaram em porcentagem da recomendação, sendo utilizadas: 0,50 e $100 \%$ das quantidades recomendadas para a cultura. Os trabalhos foram conduzidos no Departamento de Solos da Universidade Federal do Paraná, em Curitiba, Brasil, com delineamento em blocos casualizados, em arranjo fatorial $4 \times 3$. Na avaliação do desenvolvimento da cultura, foram considerados parâmetros morfológicos indicativos de qualidade, tais como massa das matérias seca e verde, altura e quantidade das hastes florais produzidas, entre outros avaliados. Houve aumento significativo da biomassa das plantas com a adição de lodo de esgoto e de fósforo mineral, havendo interação entre os dois fatores. Não houve formação de haste floral no tratamento sem adição de lodo de esgoto e de P.

Palavras-chave: Gypsophila; Lodo de esgoto; Fósforo; Morfologia.

\section{Abstract}

This green house experiment was carried out with the objective to value the influence of amounts of alkaline sewage sludge, phosphorus fertilization in the Gypsophila paniculata L. growth. The valued amounts of sewage sludge were $0,20,40$ and 60 tha $^{-1}$; and 0,50 and $100 \%$ of the official recommendation of phosphorus fertilization were tested. The seedlings were planted in the green house of the Soils Department of the Universidade Federal do Paraná, Brazil. The experimental design was the complete randomized blocks with $4 \times 3$ factorial experiments. In the crop development, some morphological parameters were valued. There was a significant increase in the dry matter of the plants with the addition of sewage sludge and phosphorus, with interaction between both factors. There was no flower formation by plants without the supply of sewage sludge and phosphorus.

Keywords: Gypsophila; Sewage sludge; Phosphorus; Morphology.

${ }^{1}$ Professora Adjunta da Pontifícia Universidade Católica do Paraná. e-mail: cyntia.maria@pucpr.br

${ }^{2}$ Professora Titular da Universidade Federal do Paraná. e-mail: bmserrat@ufpr.br 


\section{Introdução}

Diante de uma crescente preocupação mundial referente à gestão adequada de resíduos, a utilização do lodo de esgoto (LE) como fonte de nutrientes na agricultura vem surgindo como alternativa promissora de destino deste material, especialmente para um estado como o Paraná, com agricultura intensiva e extensas áreas de solos depauperados com níveis mínimos de matéria orgânica. A reciclagem agrícola do lodo, ou utilização do lodo em solos agrícolas em associação ao plantio de culturas, representaria a alternativa de menores impactos ambientais negativos e tem sido praticada em muitos países desenvolvidos como solução adequada à disposição final do produto.

Sob os pontos de vista ambiental e sanitário, sugere-se que a eficiência do LE na adubação de flores e plantas ornamentais, que se constituem em culturas não destinadas ao consumo alimentar humano, traria uma alternativa bastante promissora de aproveitamento deste material.

A Gypsophila, originária da região mediterrânea, leste europeu e da Sibéria (1), conhecida popularmente como "mosquitinho" ou "branquinha", é uma planta herbácea perene da família Caryophyllaceae, cultivada como flor de corte em ciclos anuais. É uma espécie altamente ramificada, cuja inflorescência, em panícula, sustenta um grande número de pequenas flores (1). Suas hastes florais são comumente usadas na composição de arranjos florais e buquês, podendo também ser comercializadas como flores secas. Entre as 75 espécies existentes no gênero, as mais conhecidas são a Gypsophila elegans e a Gypsophila paniculata, sendo esta última a única cultivada comercialmente como flor de corte (2).

Poucos trabalhos se reportam a essa cultura, especialmente no que se refere a respostas à adubação e a aspectos nutricionais. Wachowicz et al. (3) observaram que a ausência do elemento fósforo (P) inviabilizou a produção de Gypsophila paniculata L., pois as plantas avaliadas nessa condição de ausência não emitiram haste floral.

Associando-se os aspectos vantajosos do uso do LE na agricultura ao fato de o setor de flores e plantas ornamentais estar despontando como uma promissora alternativa econômica na agricultura de pequeno porte no Estado do Paraná e, dentro deste setor, especialmente a cultura da Gypsophila, este trabalho teve como objetivo avaliar características morfológicas associadas a vigor e à produtividade da cultura, em resposta a diferentes doses de adubação fosfatada e de LE.

\section{Material e métodos}

Foram utilizadas mudas de Gypsophila paniculata L. cv. Golan, plantadas em vasos plásticos contendo como substrato amostras de terra retiradas a uma profundidade máxima de $20 \mathrm{~cm}$, de um cambissolo distrófico álico (4), textura argilosa. Esse solo foi escolhido em função dos baixos níveis do elemento fósforo e as amostras coletadas foram peneiradas em malha $10 \mathrm{~mm}$.

O lodo de esgoto aeróbio estabilizado alcalino utilizado foi fornecido pela Companhia de Saneamento do Paraná - SANEPAR, coletado na Estação de Tratamento de Esgotos Belém, situada no município de Curitiba, estado do Paraná.

Considerando-se a recomendação para uso agrícola de 50 t.ha $^{-1}$ de lodo de esgoto em base úmida para a cultura do milho, feita por Lourenço et al. (5), utilizou-se uma dose superior e duas inferiores à dose recomendada. O lodo foi incorporado ao substrato 30 dias antes do plantio. $O$ cálculo para base seca baseouse no teor de umidade determinado no lodo coletado, de $56,74 \%$. Os tratamentos de $0 ; 8 ; 17$ e 25 t.ha $^{-1}$ corresponderam, respectivamente, a $0 ; 10,81 ; 21,63 \mathrm{e}$ $32,44 \mathrm{~g} /$ vaso de lodo de esgoto.

Utilizou-se o delineamento em blocos casualizados, em arranjo fatorial $4 \times 3$, sendo 4 níveis de doses de lodo de esgoto e 3 níveis de porcentagens da recomendação de adubação fosfatada para a cultura. Foram utilizadas três repetições, sendo uma unidade experimental constituída de três vasos.

Foram testadas doses de fósforo equivalentes a $0 ; 50$ e $100 \%$ do total recomendado para a cultura que, para solos com baixos níveis de fósforo, é de 180 kg.ha- ${ }^{-1}$ de $\mathrm{P}_{2} \mathrm{O}_{5}$ (6).

Na ocasião do plantio, foram então aplicadas as seguintes quantidades de superfosfato triplo (41\% de $\mathrm{P}_{2} \mathrm{O}_{5}$ ), por tratamento: $0,5488 \mathrm{~g} /$ vaso nos tratamentos de $100 \%$ da recomendação e $0,2744 \mathrm{~g} /$ vaso nos tratamentos de 50\% da recomendação.

Em vasos plásticos de $22 \mathrm{~cm}$ de diâmetro e com capacidade de 4,0 L, foram utilizados $2,5 \mathrm{~kg}$ de substrato de terra. As doses de lodo foram diluídas em água deionizada e acrescentadas gradualmente à terra, sendo que a mistura solo-lodo foi feita manualmente, com utensílios e recipientes plásticos. 
Foi estabelecido um intervalo de 30 dias entre a aplicação do lodo e o plantio das mudas. Nesse intervalo, o substrato sempre foi mantido úmido e coberto.

Durante o desenvolvimento da cultura, foram feitas regas diárias com água deionizada, com quantidade variável por tratamento, de acordo com a necessidade das plantas, evitando-se sempre o excesso.

Para adubação mineral de plantio, Tombolato e Furlani (6) recomendam a aplicação de $30 \mathrm{~kg} \mathrm{ha}^{-1}$ de $\mathrm{N}$ e, para os níveis de $\mathrm{K}$ encontrados no solo utilizado nesse experimento, $40 \mathrm{~kg} \cdot \mathrm{ha}^{-1}$ de $\mathrm{K}_{2} \mathrm{O}$. A recomendação não considera as quantidades fornecidas pela adubação orgânica.

$\mathrm{Na}$ adubação mineral de cobertura, a recomendação dos mesmos autores é a aplicação de $120 \mathrm{~kg} \cdot \mathrm{ha}^{-1}$ de $\mathrm{N}$ e $120 \mathrm{~kg} \cdot \mathrm{ha}^{-1}$ de $\mathrm{K}_{2} \mathrm{O}$, parcelando-se essas quantidades em três vezes, aos 30,60 e 90 dias após o plantio. As fontes utilizadas foram: uréia (45\% de $\mathrm{N})$ e $\mathrm{KCl}\left(60 \%\right.$ de $\left.\mathrm{K}_{2} \mathrm{O}\right)$.

Tanto no plantio como em cobertura, aos 30, 60 e 90 dias após, os fertilizantes foram diluídos em água deionizada e aplicados diretamente no substrato.

Devido à grande quantidade de $\mathrm{N}$ prontamente disponível pela aplicação do lodo de esgoto no substrato, optou-se por realizar a adubação nitrogenada de plantio somente aos 15 dias após, evitando-se o excesso desse elemento em alguns tratamentos no momento do plantio. Foram, portanto, aplicados $0,0833 \mathrm{~g}$ de uréia em todos os vasos de todos os tratamentos, aos 15 dias após o plantio. $\mathrm{O} \mathrm{KCl}$ foi aplicado no plantio, utilizando-se $0,0833 \mathrm{~g}$ por vaso.

Aos 33 dias após o plantio, foi efetuada a prática denominada "pinch", normalmente utilizada pelos produtores em plantios de primavera e verão. $\mathrm{O}$ "pinch" consiste na eliminação do ápice das plantas que, depois de cerca de um mês do plantio, apresenta aproximadamente 10 folhas, com o objetivo de quebra de dominância apical e, conseqüentemente, aumento da produtividade em número de hastes florais emitidas por planta. Foi realizado corte com tesoura comum.

Da mesma maneira como ocorre em plantios comerciais, os cortes das hastes florais foram sendo realizados à medida que estas atingiam o ponto de colheita, quando pelo menos $50 \%$ dos botões florais de toda a panícula estão abertos. A maior parte das hastes florais atingiu o ponto de colheita entre os 110 e os 126 dias após o plantio.

Os parâmetros morfológicos avaliados são considerados indicativos de produtividade na produção e na comercialização de flores de corte.

A partir do ponto de colheita, foram sendo avaliadas as seguintes características morfológicas das plantas:

a) número de hastes florais;

b) altura da haste floral: expressa em $\mathrm{cm} \mathrm{e}$ medida a partir do colo da planta, no ponto de corte;

c) número de ramificações primárias da haste floral: foram contadas as ramificações com mais de $10 \mathrm{~cm}$ de comprimento, originadas diretamente no eixo principal da haste. É indicativo de produtividade, pois remete ao tamanho da panícula. As ramificações em geral são cortadas pelos floristas e utilizadas em buquês e arranjos florais (Figura 1);

d) número de flores: foram contadas as flores de cada haste ou inflorescência;

e) diâmetro da flor: resultado da média de 3 flores de cada haste, foi medido com paquímetro, em mm, amostrando-se flores totalmente abertas;

f) massa de matéria fresca das hastes (em gramas): relaciona-se à produtividade $\mathrm{e}$ também à durabilidade em vaso e foi realizada em balança analítica de precisão (Mettler P 1200);

g) massa de matéria seca das hastes: após a avaliação da massa fresca, as hastes foram submetidas à secagem em estufa de ventilação forçada, $a 5^{\circ} \mathrm{C}$, até obtenção de peso constante (aproximadamente 72 horas).

Os dados foram submetidos à análise de variância e ao teste $\mathrm{F}$, analisando-se a significância de cada fator, bem como da interação dos dois fatores (doses de lodo e doses de fósforo). Foram calculadas as equações de regressão polinomial, obtendo-se as médias ajustadas pelo modelo quadrático. 


\section{Resultados e discussão}

O crescimento em biomassa das plantas de Gypsophila paniculata L. foi significativamente influenciado pelo lodo de esgoto e pela adição de fósforo. A interação dos dois fatores também foi significativa. As Figuras 1 e 2 mostram os valores de crescimento em massa das matérias verde e seca totais, respectivamente.

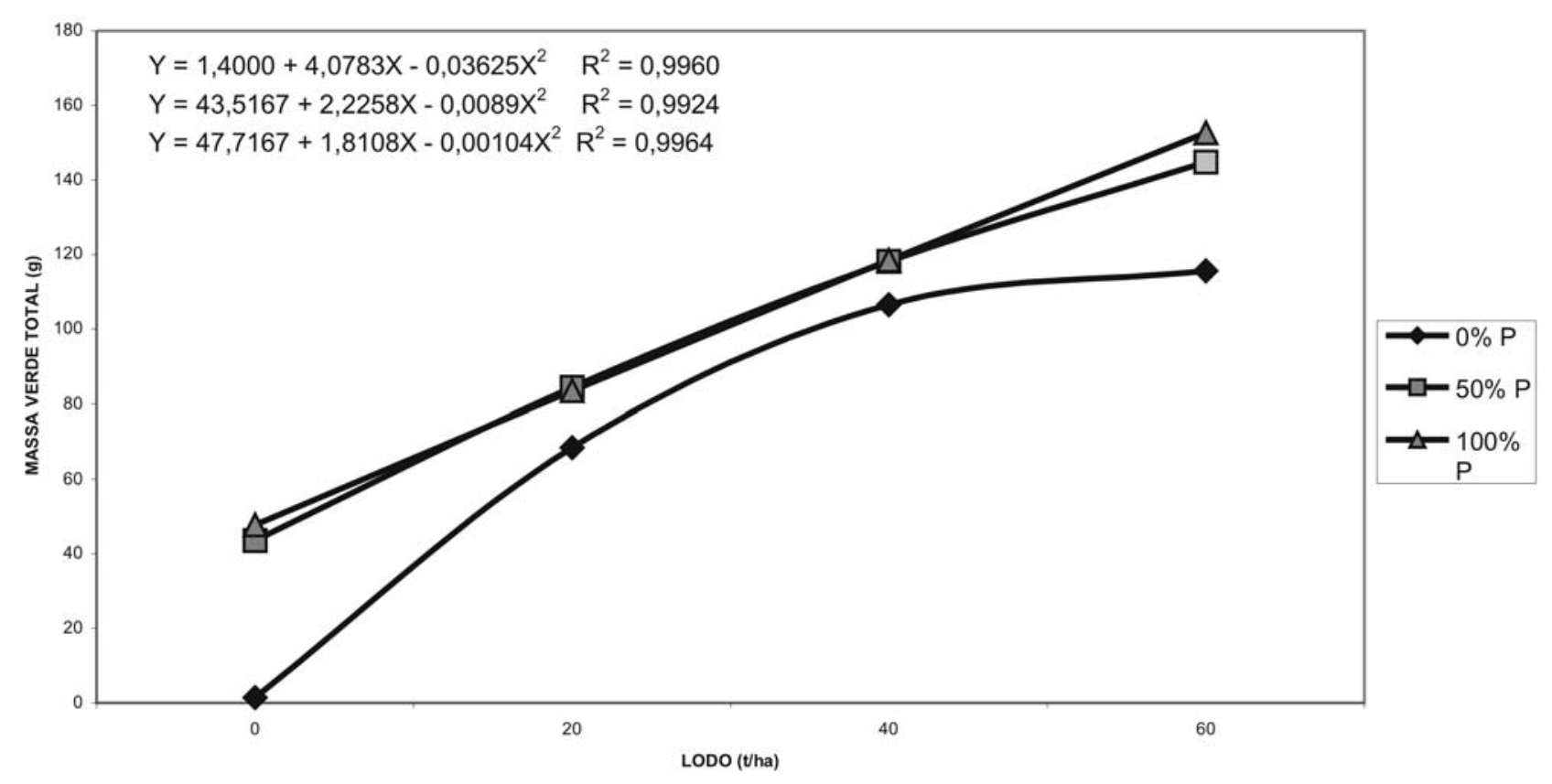

\section{FIGURA 1 - Massa da matéria verde total (g) de plantas de gypsophila paniculata l. Cultivadas em doses crescentes de lodo de esgoto e diferentes porcentagens de recomendação de adubaçãofosfatada}

A análise da massa das hastes florais (matéria verde), parâmetro indicativo de produtividade na comercialização das flores, evidencia um efeito significativo da interação do LE com o P. À medida que se aumenta o fornecimento de P mineral, reduzse a influência do LE aplicado, sendo que na dose de $100 \%$ da recomendação de $\mathrm{P}$, não houve diferença significativa entre as quantidades aplicadas de LE (Figura 1). Os maiores valores foram observados na maior dose de LE, não havendo, de maneira geral, diferença entre os níveis de P mineral fornecido, exceto na ausência de $\mathrm{P}$ e na menor dose de LE (20 t.ha $\left.{ }^{-1}\right)$.
Na dose recomendada de $\mathrm{P}(100 \%)$ houve aumento da matéria seca com o aumento do fornecimento de LE, sendo os maiores valores encontrados na maior dose (60 t.ha $\left.{ }^{-1}\right)$ (Figura 2). Quando, no entanto, não foi aplicado o fósforo mineral ou quando foi aplicado $50 \%$ da recomendação, houve uma estabilização do crescimento entre as duas maiores doses de LE testadas.

Analisando-se a matéria verde total, a estabilização do crescimento é verificada apenas na ausência de P(Figura 1). 


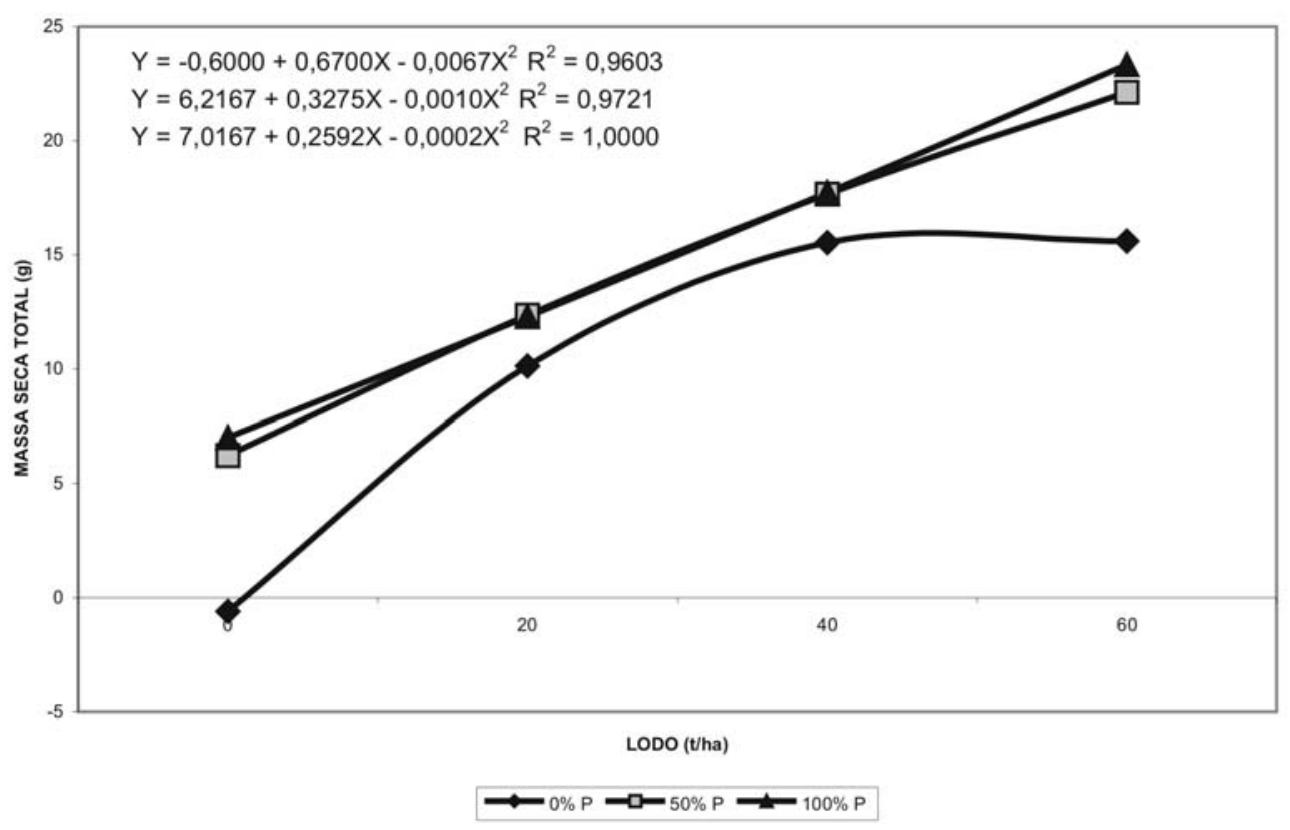

FIGURA 2 - Massa da matéria seca total (g) de plantas de gypsophila paniculata l. cultivadas em doses crescentes de lodo de esgoto e diferentes porcentagens de recomendação de adubaçãofosfatada

Quando avaliado o número de hastes florais emitidas por planta, observou-se um aumento até a dose de 40 t.ha $^{-1}$ de lodo de esgoto, acima da qual houve redução, exceto para o tratamento de $100 \%$ da recomendação de $\mathrm{P}$ (Figura 3). O maior número de hastes ocorreu na dose de 40 t.ha $^{-1}$ de LE, com $50 \%$ da recomendação de P. Na maior dose de LE $\left(60\right.$ t.ha $\left.^{-1}\right)$, houve mais hastes na dose recomendada de $\mathrm{P}(100 \%)$.

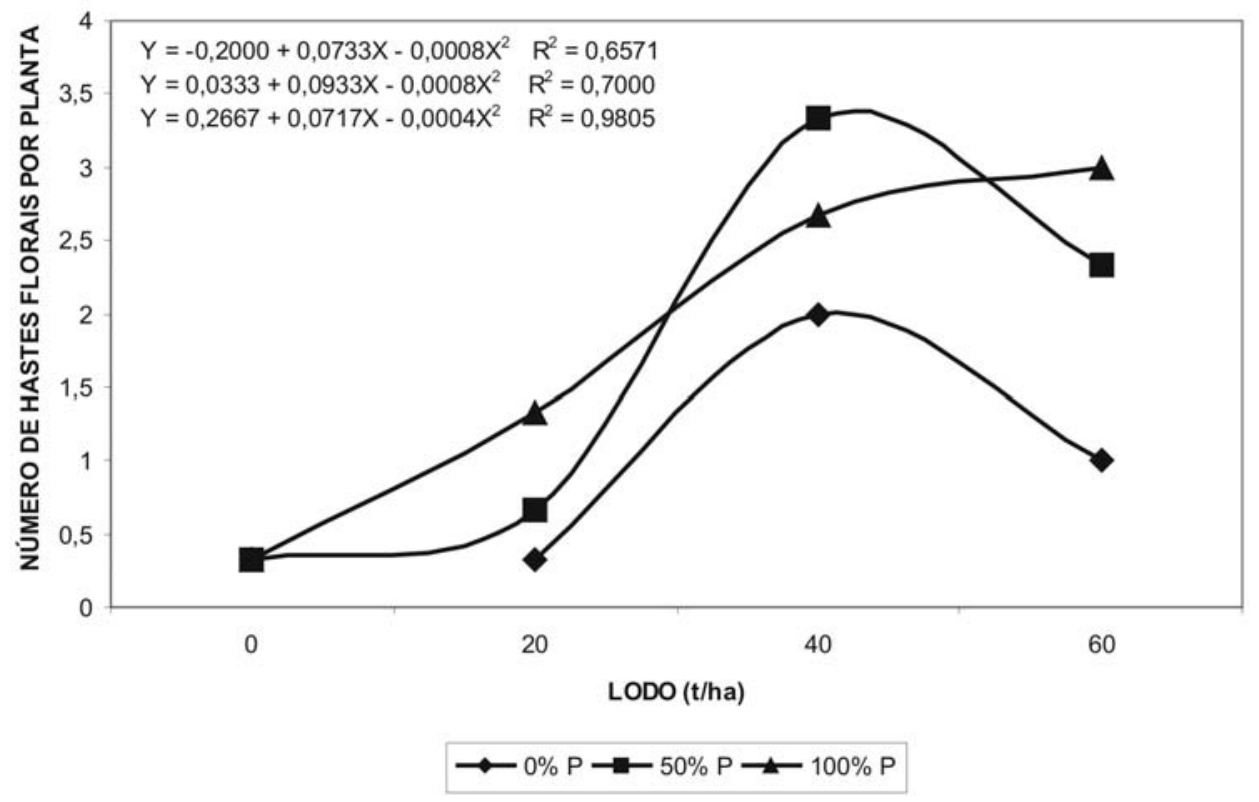

FIGURA 3 - Número de hastes florais emitidas por plantas de gypsophila paniculata l. cultivadas em doses crescentes de lodo de esgoto e diferentes porcentagens de recomendação de adubação fosfatada 


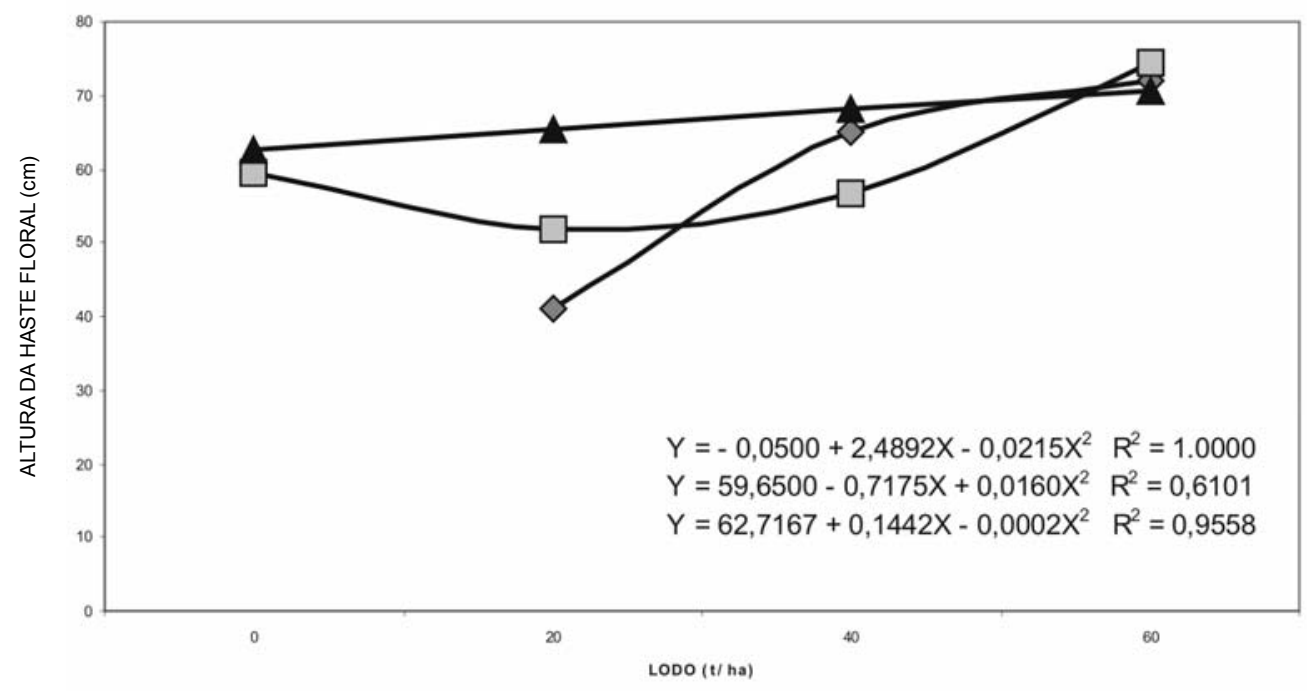

\section{FIGURA 4 - Alturas médias das hastes florais (cm) de plantas de gypsophila paniculatal. cultivadas em doses crescentes de lodo de esgoto e diferentes porcentagens de recomendação de adubaçãofosfatada}

Tendo-se em vista que a altura das hastes florais, associada à quantidade de massa verde, é um parâmetro valorizado no momento da comercialização de flores de corte em geral, considerou-se bastante positiva a resposta da cultura ao fornecimento de LE.

As hastes mais altas foram observadas nas maiores doses de LE, não havendo, porém, diferença significativa entre as doses de 40 e 60 t.ha ${ }^{-1}$ (Figura 4). Na maior porcentagem do elemento $\mathrm{P}$ aplicado, não houve influência da quantidade de LE avaliada. A quantidade de $\mathrm{P}$ fornecida influenciou a altura das plantas somente na menor dose de LE (20 t.ha-1).

A aplicação de lodo de esgoto na agricultura, como fertilizante, traz uma série de benefícios, entre os quais se destaca o aumento de produção de matéria seca e da produtividade de muitas espécies cultivadas. Silva (7) e Anjos (8) verificaram que o uso do lodo de esgoto como fertilizante em cana-de-açúcar proporcionou aumentos lineares de produtividade em biomassa e açúcar.

Comparando-se as médias de matéria seca total obtidas com Gypsophila paniculata L. neste trabalho, verifica-se um aumento de aproximadamente $100 \%$ para a primeira dose de LE avaliada $\left(20\right.$ t.ha $\left.^{-1}\right)$, chegando a cerca de $300 \%$ na dose máxima avaliada $\left(60\right.$ t.ha $\left.^{-1}\right)$. Andreoli et al. (9) citam Nascimento e Botega (10) que verificaram aumentos de produtividade da ordem de 49 a $77 \%$ na cultura do milho.
Outros parâmetros ligados à comercialização e também considerados indicativos de qualidade para a espécie estudada são o número de ramificações primárias da haste e o número de flores emitidas pelas inflorescências.

A função regulatória do fósforo no metabolismo fotossintético das folhas é um dos principais fatores limitantes do crescimento vegetal, especialmente durante o período reprodutivo. Marschner (11) afirma que há relação entre deficiência de $\mathrm{P}$, redução do número de flores e atraso da iniciação floral, sugerindo a participação do P no balanço de substâncias reguladoras do crescimento vegetal, o que se verificou também com os resultados obtidos em relação ao número de flores das plantas do tratamento sem adição de $\mathrm{P}$ e de lodo de esgoto (Figura 6), onde não houve formação de haste floral e a parte aérea remanescente teve seu crescimento bastante reduzido.

As hastes com maior número de ramificações, bem como com maior número de flores, foram encontradas nas maiores doses de LE e de P, não havendo diferença entre as doses de LE nas maiores doses de $\mathrm{P}$ (Figuras 5 e 6). Também não houve diferença entre as doses de P nas maiores doses de LE para ambos os parâmetros (número de ramificações e de flores).

O diâmetro das flores das panículas de Gypsophila paniculata L. também foi avaliado e variou entre 7 e $9 \mathrm{~mm}$, não sofrendo influência dos tratamentos avaliados. 


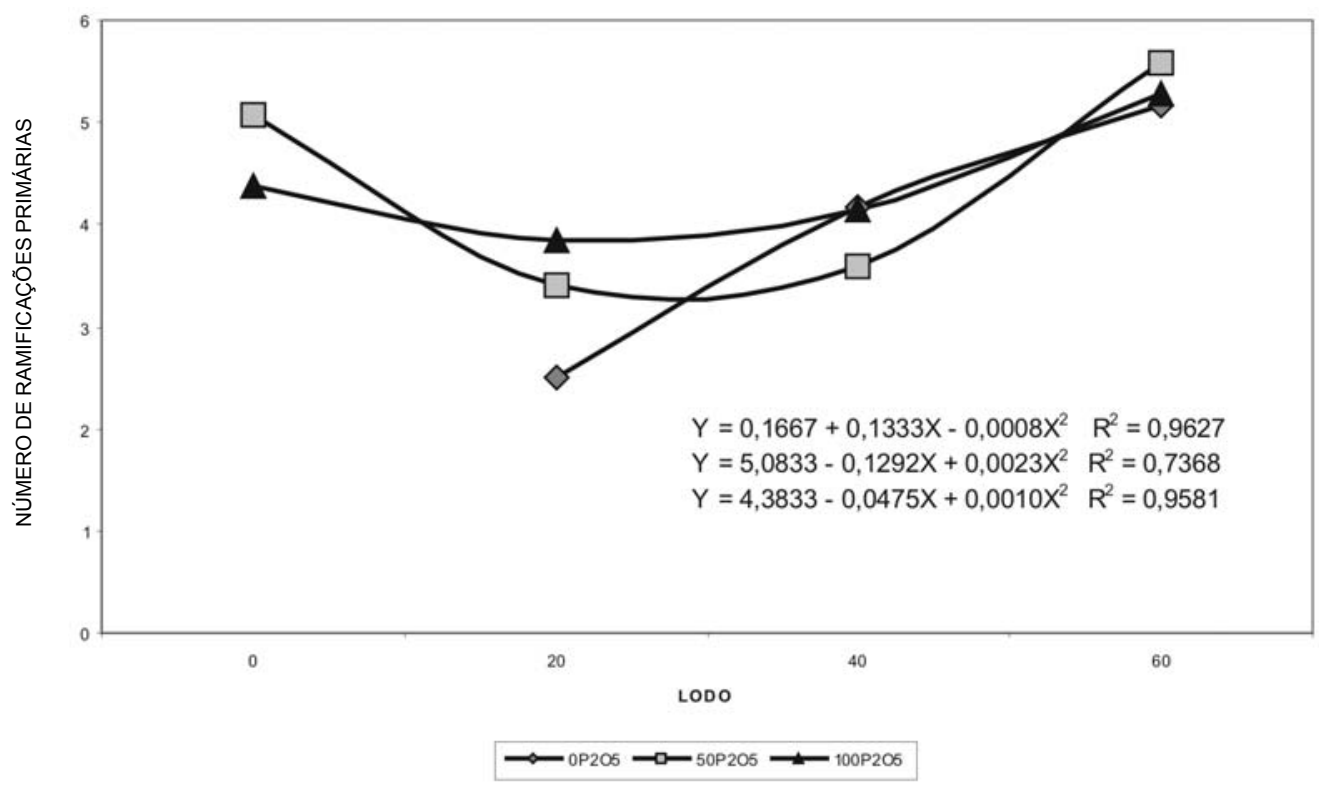

FIGURA 5 - Número de ramificações primárias emitidas em hastes florais de plantas de gypsophila paniculata l. cultivadas em doses crescentes de lodo de esgoto e diferentes porcentagens de recomendação de adubação fosfatada

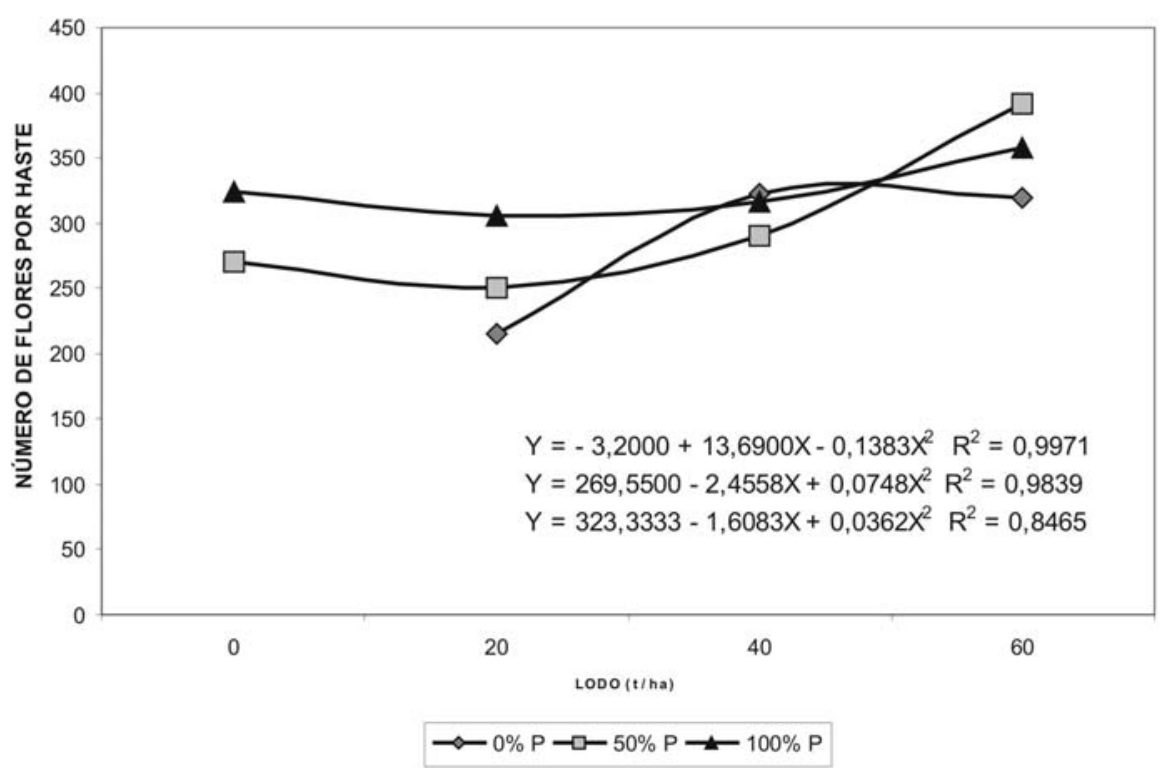

FIGURA 6 - Número de flores emitidas por hastes florais de plantas de gypsophila paniculata l. cultivadas em doses crescentes de lodo de esgoto e diferentes porcentagens de recomendação de adubação fosfatada

\section{Conclusão}

Houve aumento significativo da biomassa das plantas de Gypsophila paniculata L. com a adição de lodo de esgoto e fósforo mineral, havendo interação entre os dois fatores. No tratamento sem adição de LE e P não houve formação de haste floral e a parte aérea remanescente teve seu crescimento significativamente reduzido. 
Associada a outros parâmetros, como a altura e, especificamente para a Gypsophila, o número de ramificações primárias da haste, a quantidade de matéria verde é um fator indicativo de qualidade na comercialização de flores de corte em geral. Considerouse, portanto, bastante positiva a resposta da cultura ao fornecimento de LE. Os maiores valores de massa de matéria verde de hastes florais foram observados nas maiores doses de LE, não havendo diferença entre os níveis de $\mathrm{P}$ fornecido.

\section{Referências}

1. Bosa N, Calvete EO, Nienow AA, Suzin M. Rooting and aclimatization of micropropagated Gypsophila paniculata plants. Hortic. Bras. 2003; 21(2):207-10.

2. Arteaga AD, Amezquita MO. Efecto de la zona de localización del esqueje en la planta madre, sobre el enraizamento de Gypsophila paniculata L. Agronomia Colombiana. 1990; 7:47-53.

3. Wachowicz CM, Zampier AC, Giroldo AF, Bruginski DH, Lombardi K, Winkler L, Sakai P, Prevedello BMS. Efeito de doses crescentes de fósforo no desenvolvimento de Gypsophila paniculata L. cv. Golan. Revista Brasileira de Fisiologia Vegetal. 1999; 11:158.

4. EMBRAPA. Centro Nacional de Pesquisa de Solos. Sistema brasileiro de classificação de solos. Rio de Janeiro: Embrapa Solos; 1999. 412 p.
5. Lourenço RS, dos Anjos ARM, Libardi PL, Medrado MJS. Efeito do lodo de esgoto na produtividade de milho e feijão, no sistema de produção de bracatinga. Sanare (Rev. Técnica da Sanepar). 1996; 5(5):90-92.

6. Tombolato AFC, Furlani AMC. Ornamentais e flores - Gypsophila. In: Boletim Técnico 100 Recomendações de adubação e calagem para o Estado de São Paulo. $2^{\mathrm{a}}$ ed. Campinas: IAC FUNDAG; 1997. p. 214.

7. Silva FC. Uso agronômico do lodo de esgoto: efeitos em fertilidade do solo e qualidade da canade-açúcar. Escola Superior de Agricultura "Luiz de Queiroz" [tese]. São Paulo: Universidade Estadual de São Paulo; 1995.

8. Anjos ARM. Lixiviação de espécies químicas em latossolos sucessivamente tratados com biossólido e disponibilidade de metais pesados para plantas de milho. Escola superior de Agricultura "Luiz de Queiroz" [tese]. São Paulo: Universidade de São Paulo; 1999.

9. Andreoli CV, Fernandes F, Domaszak SC. Reciclagem agrícola do lodo de esgoto: estudo preliminar para definição de critérios para uso agronômico e de parâmetros para normatização ambiental e sanitária. Curitiba: Sanepar; 1997. 81p.

10. Nascimento EB, Botega JC. Relatório interno. Curitiba: EMATER; 1996.

11. Marschner H. Mineral nutrition of higher plant. $2^{\mathrm{a}}$ ed. New York: Academy; 1995. 889 p.

Recebido em/Received in: January 10, 2006 Aceito em/Accepted in: July 03, 2006 